\title{
Glucagon-Stimulating Activity of 20 Amino Acids in Dogs
}

\author{
Dalva Marreiro Rocha, Gerald R. Faloona, and Roger H. Unger \\ From the Department of Internal Medicine, The University of Texas \\ Southwestern Medical School at Dallas and Veterans Administration Hospital, \\ Dallas, Texas 75216
}

\begin{abstract}
A в S T R A C T The effect of 20 L-amino acids upon pancreatic glucagon secretion has been studied in conscious dogs. Each amino acid was administered intravenously over a $15 \mathrm{~min}$ period in a dose of $1 \mathrm{mmole} / \mathrm{kg}$ of body weight to a group of four or five dogs. Pancreatic glucagon and insulin were measured by radioimmunoassay. 17 of the 20 amino acids caused a substantial increase in plasma glucagon. Asparagine had the most glucagonstimulating activity (GSA), followed by glycine, phenylalanine, serine, aspartate, cysteine, tryptophan, alanine, glutamate, threonine, glutamine, arginine, ornithine, proline, methionine, lysine, and histidine. Only valine, leucine, and isoleucine failed to stimulate glucagon secretion, and isoleucine may have reduced it. No relationship between glucagon-stimulating activity and insulin-stimulating activity was observed. The amino acids which enter the gluconeogenic pathway as pyruvate and, which are believed to provide most of the amino acid-derived glucose, had a significantly greater GSA than the amino acids which enter as succinyl $\mathrm{CoA}$ or as $\alpha$-ketoglutarate. However, pyruvate itself did not stimulate glucagon secretion. The R-chain structure of the amino acid did not appear to be related to its GSA, except that the aliphatic branched chain amino acids, valine, leucine, and isoleucine, were devoid of GSA.
\end{abstract}

\section{INTRODUCTION}

The ingestion of a protein meal is accompanied in man by a prompt and substantial increase in the secretion of pancreatic glucagon $(1,2)$. Earlier studies in dogs had shown a similar glucagon response to the i.v. administration of a 10 amino acid mixture, thus establishing hyper-

This work was presented at the Annual Meeting of the Southern Section of the American Federation for Clinical Research, New Orleans, La., 27 January 1972.

Dr. Marreiro is a Research Fellow of the Fundação de Amparo A Pesquisa Do Estado De São Paulo, Brazil.

Received for publication 2 March 1972 and in revised form 13 April 1972. aminoacidemia as an important stimulus of the pancreatic alpha cell (3). However, the effects of most of the individual amino acids upon pancreatic glucagon secretion have not been studied; arginine has been reported to stimulate glucagon secretion in humans (4-6) and in dogs (7), and alanine (8) and histidine (7) in dogs. Alanine, arginine, valine, leucine, tryptophane, tyrosine, glycine, and glutamate have been studied in rats by Assan and Hanoune ${ }^{1}$ and all were reported to stimulate glucagon in the large doses employed.

The present studies were designed to determine the relative glucagon-stimulating activity of each of 20 amino acids and their effect upon insulin secretion, and to search for relationships between the hormone-stimulating activities of the amino acids, their metabolic fates, and their chemical structures.

\section{METHODS}

Each amino acid was administered at $\mathrm{pH} 7.4$ to a group of four or five conscious dogs after an $18 \mathrm{hr}$ fast in a dose of $1 \mathrm{mmole} / \mathrm{kg}$ of body weight in $80 \mathrm{ml}$ of water ${ }^{2}$ for $15 \mathrm{~min}$ through indwelling catheters previously implanted in a crural vein. One-quarter of the dose was given as a rapid priming injection, and the remaining threequarters of the dose administered at a constant rate thereafter. For many of the amino acids, the dose employed probably exceeded the maximal amount of an individual amino acid ingested during a normal protein meal, and the concentrations produced are probably unphysiologically high. In the case of aspartate, tryptophan, glutamate, and cysteine, the dose employed induced vomiting in all dogs, possible evidence that toxic concentrations were attained.

Each dog was used for two amino acid experiments with an interval of at least 2 days between experiments.

The amino acids were purchased from Sigma Chemical

${ }^{1}$ Assan, R., and J. Hanoune. 1972. Effects on rat plasmatic glucagon and glucagon-like immunoreactivity of eight amino acids (intragastric and intraperitoneal loads); comparison with intragastric loads of six sugars. Submitted for publication.

2 The amino acids tryptophan, aspartate, methionine, cysteine, phenylalanine, and leucine were relatively insoluble and were, therefore, administered in a volume of $160 \mathrm{ml}$. 
Co., St. Louis, Mo.; ICN Nutritional Biochemicals Div.. Cleveland, Ohio; Mann Research Labs, Inc., New York; Pfanstiehl Chemical Corp., Waukegan, Ill.; Fisher Scientific Company, Pittsburgh, Pa.; and pyruvate from Matheson Coleman \& Bell, Norwood, Ohio.

A solution of each amino acid in a concentration of $0.1 \mathrm{M}$ was tested to determine if it affected directly any of the measurements. Cysteine gave a reading of $>300 \mathrm{mg} / 100$ $\mathrm{ml}$ for glucose and $4 \mu \mathrm{U} / \mathrm{ml}$ for insulin. Tryptophan gave a reading of $217 \mathrm{mg} / 100 \mathrm{ml}$ for glucose. Otherwise, none influenced either the insulin or glucagon assays.

Blood specimens were obtained at frequent intervals before, during, and after the amino acid infusion from a previously implanted indwelling catheter reposing in the inferior vena cava. Pancreatic glucagon was measured by radioimmunoassay (9). The immunoassay system for glucagon employed in these studies was as follows: $15 \mathrm{pg}$ glucagon ${ }^{125} \mathrm{I}^{3}, 1000 \mathrm{U}$. Trasylol ${ }^{4} 0.2 \mathrm{ml}$ of plasma sample or standard, and antiserum $30 \mathrm{~K}$, which is highly specific for pancreatic glucagon, at a final dilution of $1: 60,000$, in a total volume of $1.2 \mathrm{ml}$. The tubes were incubated for 4 days at $4^{\circ} \mathrm{C}$. Free and bound glucagon- ${ }^{125} \mathrm{I}$ were separated with dextran-coated charcoal (10). Insulin was measured by the radioimmunoassay of Yalow and Berson (11), as modified by Herbert, Lau, Gottlieb, and Bleicher (10). Glucose was determined by the Hoffman ferricyanide method (12), using the Technicon Autoanalyzer.

All dogs appeared to be well at the time of their experiment two days or more after the surgical placement of the indwelling catheters. Dogs with a temperature above normal $\left(103^{\circ}\right)$, leucocyte count above 30,000 per $\mathrm{mm}^{3}$, or a hematocrit below $35 \%$, were not employed in these studies.

\section{RESULTS}

Glucagon-stimulating activity. The mean levels of glucagon, insulin, and glucose before, during, and after the infusion of each of the 20 amino acids appear in Table I. Except for valine, leucine, and isoleucine, all of the amino acids tested appeared to stimulate a prompt rise in plasma glucagon. The significance of these changes is indicated for each amino acid in Table I.

In order to obtain a single value which would reflect the increase in glucagon secretion attributable to an amino acid infusion, the area above the baseline for 30 min after the start of the infusion was calculated in each experiment; the mean of the "areas" of each group of experiments was divided by the $30 \mathrm{~min}$, to give a mean increment in plasma glucagon. This value is henceforth referred to as the "glucagon-stimulating activity" or $\mathrm{GSA}^{\circ}$ of the amino acid.

The results are shown in Fig. 1, grouped in decreasing order of GSA. Alanine, regarded as a powerful glucagonstimulating amino acid, had a GSA of $58.5 \mathrm{pg} / \mathrm{ml}$ (sEM \pm 6.3) and ranked eighth in this scheme. Asparagine ap-

\footnotetext{
${ }^{3}$ Glucagon was obtained from Cambridge Nuclear Corp., Cambridge, Mass.

'FBA Pharmaceuticals, New York.

- Technicon Corporation, Tarrytown, N. Y.

- Abbreviations used in this paper: GSA, glucagon-stimulating activity; ISA, insulin-stimulating activity.
}

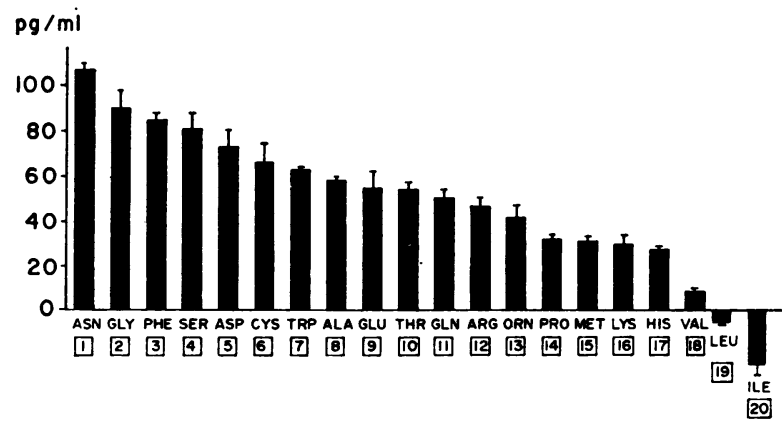

FIGURE 1 Glucagon-stimulating activity (GSA) of $1 \mathrm{mmole} /$ $\mathrm{kg}$ of $20 \mathrm{~L}$-amino acids in the dog in decreasing order of activity. Numbers refer to rank of GSA.

peared to be the most potent glucagon stimulator and histidine the weakest, while valine, leucine, and isoleucine were devoid of GSA. It is clear then, that in the doses employed 17 of the 20 amino acids examined had GSA ranging from $27 \mathrm{pg} / \mathrm{ml}(\mathrm{SEM} \pm 5)$ to $117 \mathrm{pg} / \mathrm{ml}$ (SEM \pm 17).

Insulin-stimulating activity (ISA). In order to determine if a relationship between the glucagon-stimulating activity and the insulin-stimulating activity of these amino acids could be demonstrated, a calculation similar to that used for obtaining GSA was made for insulinstimulating activity (ISA) of the 20 amino acids (Fig. 2). Only five amino acids, tryptophan, leucine, aspartate, isoleucine, and glutamate had ISA of $5 \mu \mathrm{U} / \mathrm{ml}$ or greater. From the rank of each amino acid in terms of ISA and GSA (Fig. 2) it is apparent that no relationship between them exists, an impression which is born out by correlation analysis $(r=-0.358)$. Leucine and isoleucine, which rank very high as insulin stimulators, are devoid of GSA, while asparagine, serine, and alanine, which rank very high in GSA, are very weak insulin stimulators.

These results appear to differ in a quantitative sense from those of Floyd, Fajans, Conn, Knopf, and Rull obtained in humans (13) in terms of rank of ISA.

Relationship between GSA and ISA of amino acids and their metabolic fates. Because glucagon is widely regarded as a potent gluconeogenic hormone, an effort was made to determine if the GSA of the various amino acids bears a relationship to their participation in gluconeogenesis and thus supports a regulatory role for glucagon in this pathway. Fig. 3 separates the amino acids into groups according to the currently accepted point or points of entry of their carbon skeletons into metabolic pathways leading either to gluconeogenesis or to ketogenesis $(14,15)$. Five of the amino acids, threonine, glycine, alanine, serine, and cysteine, are metabolized di-. rectly to pyruvate, and pass via oxaloacetate to phospho- 
TABLE I

The Effect of 20'Amino Acids and of Pyruvate (1 mmole/kg per $15 \mathrm{~min}$ ) on Glucose, Insulin, and Glucagon

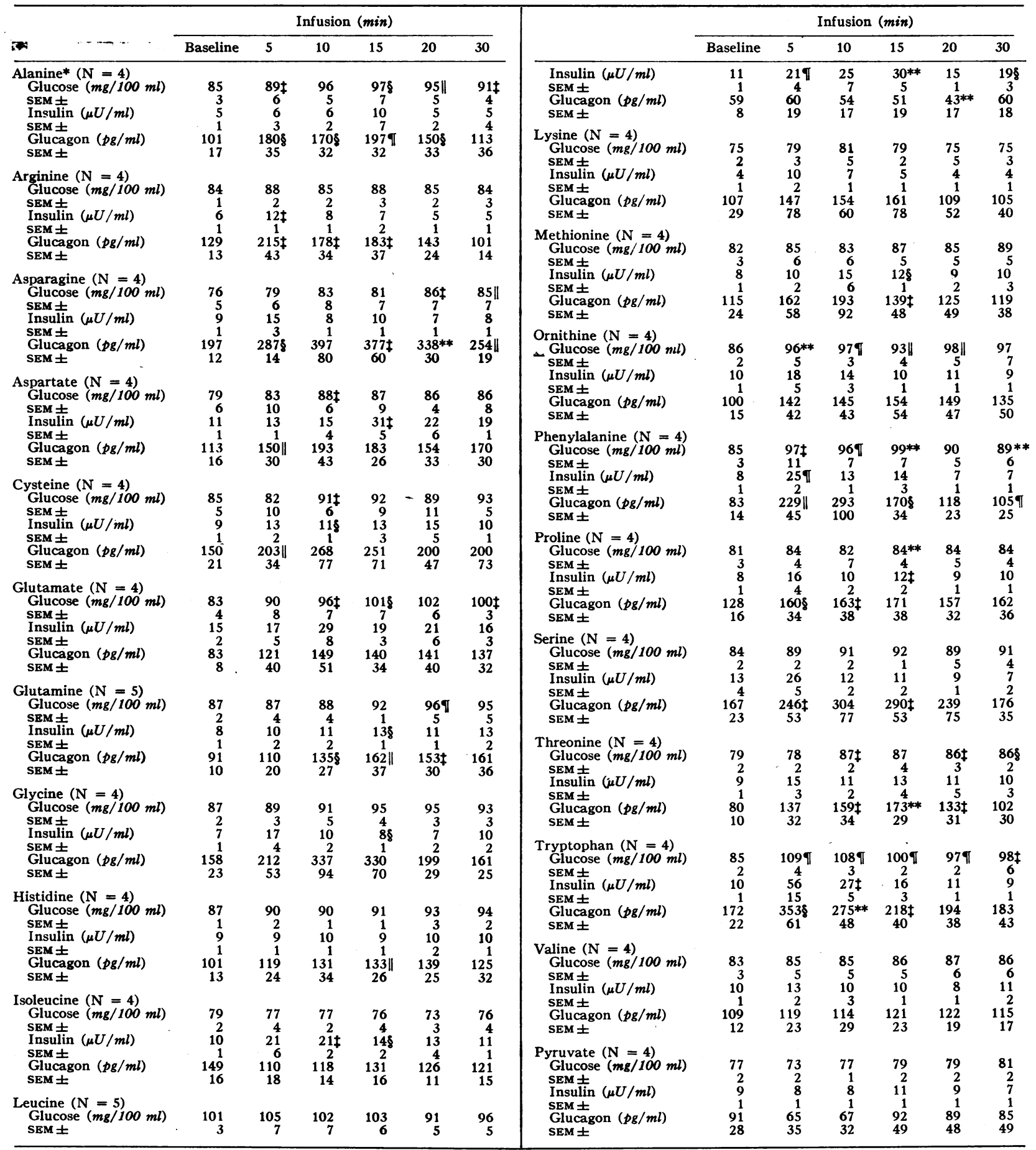

N, number of dogs.

$P$ values: $\ddagger<0.05, \&<0.02, \|<0.025$, $\mid<<0.005, * *<0.01$. 


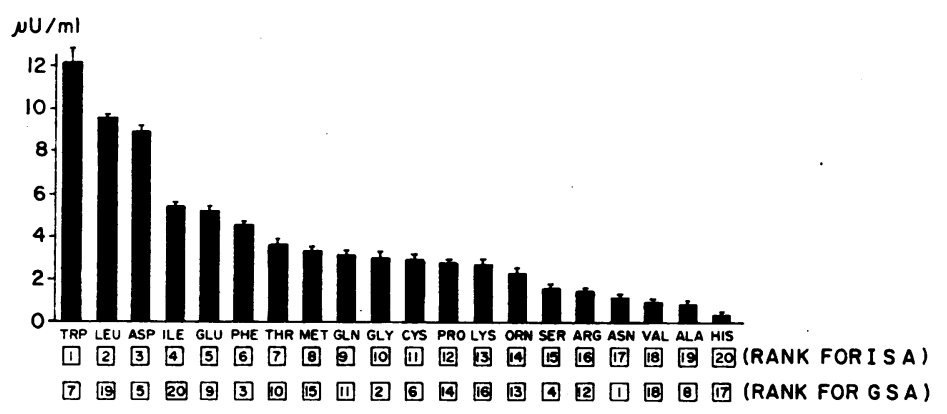

FIGURE 2 Insulin-stimulating activity (ISA) of $1 \mathrm{mmole} / \mathrm{kg}$ of 20 $\mathrm{L}$-amino acids in the dog in decreasing order of activity.

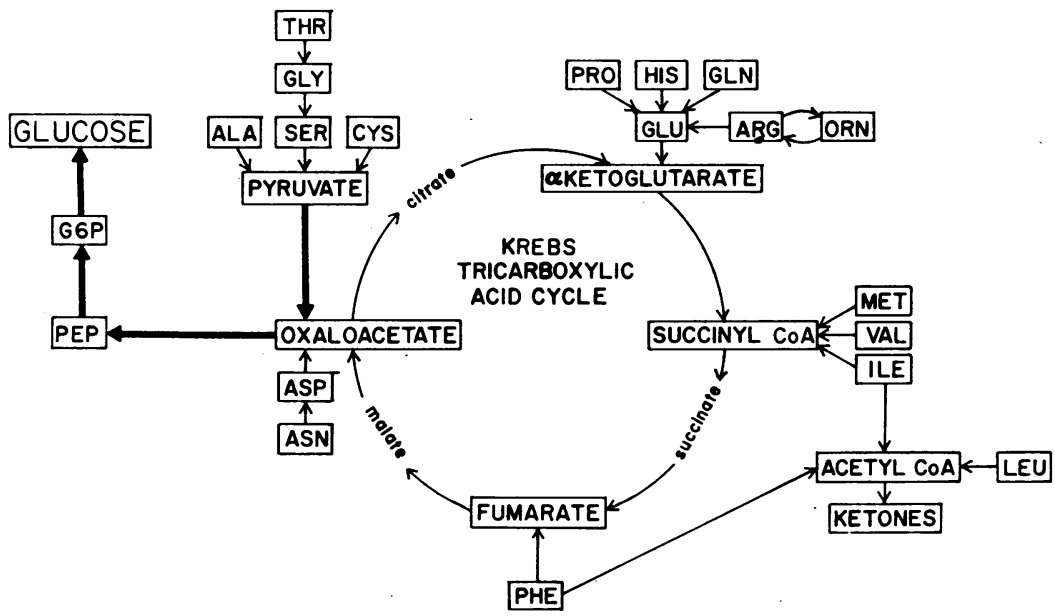

FIGURE 3 Entry points of carbon skeletons of amino acids into gluconeogenic and ketogenic pathways $(14,15)$.

enol pyruvate. According to Felig, ${ }^{7}$ this group of amino acids, primarily alanine, probably gives rise to between 75 and $90 \%$ of amino acid-derived glucose. Carbon skeletons of two other amino acids, asparagine and its derivative, aspartate, may enter the Krebs cycle as oxaloacetate and pass directly into the gluconeogenic pathway via phosphoenol pyruvate. All of the other gluconeogenic amino acids enter at distal points; half of the carbon skeleton of phenylalanine enters the Krebs cycle as fumarate, those of isoleucine, methionine and valine enter as succinyl $\mathrm{CoA}$, and those of arginine and ornithine, histidine, proline, glutamine, and glutamate enter as $\alpha$-ketoglutarate. One amino acid, namely leucine, is nongluconeogenic and enters the Krebs cycle as acetyl CoA, while the entry point of lysine is unknown (15). Tryptophan generates alanine $(14,15)$.

In Table II the GSA's of these groups of amino acids are compared with an index of their in vivo contribution to gluconeogenesis, namely, the basal splanchnic exchange rates in man, as recently reported by Felig and

\footnotetext{
${ }^{7}$ Personal communication.
}

Wahren (16). All of the amino acids which enter as pyruvate, and which, according to Felig and Wahren (16), have a positive splanchnic exchange rate which totals more than $100 \mu$ moles/min, had a mean GSA of $70 \mathrm{pg} /$ $\mathrm{ml}(\mathrm{SEM} \pm 7)$. This is significantly greater $(P<0.005)$ than that of the amino acids entering as succinyl $\mathrm{CoA}$,

TABLE II

Entry Points of the Carbon Skeletons of the Amino Acids

\begin{tabular}{|c|c|c|c|}
\hline & Pyruvate & $\alpha$-Ketoglutarate & Succinyl CoA \\
\hline $\begin{array}{l}\text { GSA }(p g / m l) \\
\text { Mean } \pm \text { SEM }\end{array}$ & $\stackrel{70( \pm 7)}{L} P$ & $\begin{array}{l}42( \pm 4) \\
0.01]\end{array}$ & $\begin{array}{l}14( \pm 9) \\
0.005\end{array}$ \\
\hline $\begin{array}{l}\text { Splanchnic exchange* } \\
\text { (umoles/min) }\end{array}$ & 102 & 18 & 3 \\
\hline $\begin{array}{l}\text { ISA }(\mu U / m l) \\
\text { Mean 土SEM }\end{array}$ & $2.5( \pm 0.5)$ & $2.6( \pm 0.7)$ & $3.2( \pm 1.3)$ \\
\hline $\begin{array}{l}\text { I/G } \\
\quad \text { Mean 土SEM }\end{array}$ & $0.85( \pm 0.2)$ & $1.34( \pm 0.3)$ & $43.8( \pm 41)$ \\
\hline
\end{tabular}

* From Felig and Wahren (16). 
which had a GSA totaling $14 \mathrm{pg} / \mathrm{ml}$ (SEM \pm 9 ) and those entering as $\alpha$-ketoglutarate, which had a GSA totaling $42 \mathrm{pg} / \mathrm{ml}(\mathrm{SEM} \pm 4)$. Asparagine and aspartate had GSA's in the range of the pyruvigenic group, but their splanchnic exchange rates are unknown.

Neither the ISA's nor the molar insulin: glucagon ratio $^{8}$ of the three groups of amino acids differed significantly from one another, although the group entering as pyruvate had the lowest ISA and the lowest insulin: glucagon ratio.

Glucagon-stimulating activity of pyruvate. In order to determine if pyruvate itself was responsible for the increased GSA of the pyruvigenic amino acids, $1 \mathrm{mmole} /$ $\mathrm{kg}$ of pyruvate was infused in a manner identical to that used for the amino acids. No increase in glucagon was observed (Table I).

Glucagon-stimulating activity and amino acid R-chain structure. To determine if the GSA of amino acids is the consequence of a common structural feature, the chemical structure of their $\mathrm{R}$-groups was examined in relation to GSA. No clear-cut relationship between the structure or the size of the R-group and ability to stimulate glucagon was observed.

For example, glycine, with an R-group consisting only of a hydrogen atom, ranked second in GSA, while phenylalanine with its large benzene ring ranked third. One seemingly definite structure-function relationship was observed, however. Amino acids with branched aliphatic $\mathrm{R}$-chains, valine, leucine, and isoleucine, were devoid of GSA. In fact, isoleucine, and perhaps leucine as well, appeared to cause a modest reduction in glucagon concentration.

\section{DISCUSSION}

These studies reveal that in the supraphysiologic doses employed in this study, most of the amino acids tested have substantial GSA in the dog. Of 20 amino acids tested, only three, valine, isoleucine, and leucine failed to stimulate glucagon secretion. It seems probable, then, that the glucagon response to the ingestion of protein is influenced by most of the amino acids absorbed.

Glucagon is widely regarded as a potent gluconeogenic hormone which may play a central role in the regulation of exogenous gluconeogenesis. It is, therefore, of interest that glucagon secretion is stimulated most strongly by those amino acids which contribute the most to amino acid-derived gluconeogenesis; alanine and the other amino acids which enter the gluconeogenic pathway as pyruvate and which, according to Felig, generate 75$90 \%$ of amino acid-derived glucose, have significantly greater glucagon-stimulating activity than amino acids

\footnotetext{
${ }^{8}$ Molar ratio of insulin: glucagon $=(\mu \mathrm{U} / \mathrm{ml}) /(\mathrm{pg} / \mathrm{ml}) \times$ 23.3.

- Personal communication.
}

which enter as succinyl CoA or $\alpha$-ketoglutarate. Only asparagine and aspartate, which enter as oxaloacetate, and phenylalanine, which enters as fumarate, have GSA comparable to the "pyruvigenic" group, but their relative contribution to gluconeogenesis is undetermined. Leucine, the only exclusively nonglucogenic amino acid tested, was devoid of GSA, confirming the report of Pek, Fajans, Floyd, Knopf, and Conn (1).

Although it should be kept in mind that these results reflect relative molar potency in a supraphysiologic concentration range, and do not necessarily indicate relative physiologic potency, they are compatible with a system of feedback regulation of amino acid disposition by the amino acid concentration. However, the fate of an amino acid depends not only upon the glucagon response, but also upon the insulin response; an increase in insulin, a potent antigluconeogenic hormone, would reduce gluconeogenic activity and spare amino acids for incorporation into protein. The ISA and insulin: glucagon ratios of the most gluconeogenic amino acids which enter as pyruvate were lower than the other groups, but not significantly so. The complexity of the hormonal response to proteininduced hyperaminoacidemia is apparent, if one considers the variation in amino acid composition of the ingested proteins, the varying catabolic rates of each amino acid, the influence of simultaneously absorbed carbohydrate and fat, the influence of the various gut hormones, and the conditioning of the islet cell responses by antecedent diet (17). Only by simulating the postprandial level of each amino acid, could information of physiologic significance be obtained.

But these results may provide other potentially significant information. First, the fact that pyruvate itself is devoid of GSA indicates either that the marked activity of the pyruvate precursor amino acids does not involve their metabolism to pyruvate, or, that pyruvate is not readily admitted to the alpha cell. The recent report of Fajans et al. (18), indicating that a nonmetabolizable analog of arginine has GSA would favor the former hypothesis.

The fact that virtually all nitrogenous precursors of glucose, but not pyruvate, lactate ${ }^{10}$ glycerol,${ }^{10}$ or fructose ${ }^{1}$ cause a prompt and substantial increase in glucagon secretion and thus would enhance their own catabolism to glucose may have physiological implications in terms of the over-all economy of amino acids, the most precious of the precursors of glucose. It may be that the powerful GSA of certain nitrogenous precursors of glucose increases conversion of amino acids to glucose during periods of amino acid abundance, such as after a large protein meal, but, at other times, when glucagon levels are unstimulated, more expendable non-nitrogenous precursors would be used preferentially for gluconeogenesis.

${ }^{10}$ Unpublished observations. 
In starvation, for example, glucagon rises only slightly and transiently (19) and returns to near-normal levels soon thereafter (20), when amino acid conservation becomes evident.

\section{ACKNOWLEDGMENTS}

This work was supported by National Institutes of Health Grant AM 02700-14; Hoechst Pharmaceutical Company, Somerville, N. J.; The Upjohn Co., Kalamazoo, Mich; Pfizer Laboratories, New York; Bristol Myers Company, New York; Eli Lilly \& Co., Indianapolis, Ind.; Wm. S. Merrell Co., Cincinnati, Ohio; Mead Johnson Research Center, Evansville, Ind.; and Dallas Diabetes Association, Dallas, Tex.

\section{REFERENCES}

1. Pek, S., S. S. Fajans, J. C. Floyd, Jr., R. K. Knopf, and J. W. Conn. 1969. Effects upon plasma glucagon of infused and ingested amino acids and of protein meals in man Diabetes. 18: 328.

2. Müller, W. A., G. R. Faloona, E. Aguilar-Parada, and R. H. Unger. 1970. Abnormal alpha-cell function in diabetes. N. Engl. J. Med. 283: 109.

3. Ohneda, A., E. Aguilar-Parada, A. M. Eisentraut, and R. H. Unger. 1968. Characterization of response of circulating glucagon to intraduodenal and intravenous administration of amino acids. J. Clin. Invest. 47: 2305.

4. Assan, R., G. Rosselin, and J. Dolais. 1967. Effets sur la glucagonémie des perfusions et ingestions d'acides aminés. J. Ann. Diabétol. Hôtel Dieu. 7: 25.

5. Fajans, S. S., J. C. Floyd, Jr., R. F. Knopf, and J. W. Conn. 1967. Effect of amino acids and proteins on insulin secretion in man. Recent Prog. Hormone Res. 23 : 617.

6. Unger, R. H., E. Aguilar-Parada, W. A. Müller, and A. M. Eisentraut. 1970. Studies of pancreatic alpha cell function in normal and diabetic subjects. J. Clin. Invest. 49: 837.

7. Kaneto, A., and K. Kosaka. 1971. Stimulation of glu- cagon secretion by arginine and histidine infused intrapancreatically. Endocrinology. 88: 1239.

8. Müller, W. A., G. R. Faloona, and R. H. Unger. 1971. The effect of alanine on glucagon secretion. J. Clin. Invest. 50 : 2215.

9. Aguilar-Parada, E., A. M. Eisentraut, and R. H. Unger. 1969. Pancreatic glucagon secretion in normal and diabetic subjects. Am. J. Med. Sci. 257: 415.

10. Herbert, V., K-S. Lau, C. W. Gottlieb, and S. J. Bleicher. 1965. Coated charcoal immunoassay of insulin. J. Clin. Endocrinol. Metab. 25: 1375.

11. Yalow, R. S., and S A. Berson. 1960. Immunoassay of endogenous plasma insulin in man. J. Clin. Invest. 39: 1157.

12. Hoffman, W. S. 1937. A rapid photoelectric method for the determination of glucose in blood and urine. J. Biol. Chem. 120: 51 .

13. Floyd, J. C., Jr., S. S. Fajans, J. W. Conn, R. F. Knopf, and J. Rull. 1966. Stimulation of insulin secretion by amino acids. J. Clin. Invest. 45: 1487.

14. Lehninger, A. L. 1970. Biochemistry. Worth Publishers, Inc., New York.

15. Lardy, H. A. 1970. Gluconeogenesis. Pathogen. Diabet. Mellitus Proc. Nobel Symp. 13. 199.

16. Felig, P., and J. Wahren. 1971. Amino acid metabolism in exercising man. J. Clin. Invest. 50: 2703.

17 Müller, W. A., G. R. Faloona, and R. H. Unger. 1971. The influence of the antecedent diet upon glucagon and insulin secretion. N. Engl. J. Med. 285: 1450.

18. Fajans, S. S., R. Quibrera, S. Pek, J. C. Floyd, Jr., H. N. Christensen, and J. W. Conn. 1971. Stimulation of insulin release in the $\operatorname{dog}$ by a nonmetabolizable amino acid. Comparison with leucine and arginine. $J$. Clin. Endocrinol. 33: 35.

19. Aguilar-Parada, E., A. M. Eisentraut, and R. H. Unger. 1969. Effects of starvation on plasma pancreatic glucagon in normal man. Diabetes. 18: 717.

20. Marliss, E. B., T. T. Aoki, R. H. Unger, J. Stuart Soeldner, and G. F. Cahill, Jr. 1970. Glucagon levels and metabolic effects in fasting man J. Clin. Invest. 49 : 2256. 